\title{
PROTEÍNA SOBREPASANTE EN OVINOS ALIMENTADOS CON RESIDUO DE COSECHA AMONIFICADO
}

\author{
Michael Benito Q. ${ }^{1}$, Felipe San Martín H. ${ }^{2}$, Fernando Carcelen C. ${ }^{2}$ y \\ Teresa Arbaiza F. ${ }^{2}$
}

\section{Bypass protein in the diet of sheep fed urea treated crop residues}

\begin{abstract}
During the dry season months from June to August, 56 randomly selected female Junin breed sheep at the IVITA-El Mantaro Research Station, Huancayo, Peru, were fed during 21 days four different diets designed to determine the effect of bypass protein (fish meal) on weight gain in sheep fed urea treated crop residues (barley straw with amonia). The four diets were comprised of: 1) $230 \mathrm{~g}$ of cotton cake, 2) $161 \mathrm{~g}$ of cotton cake and $42 \mathrm{~g}$ of fish meal, 3) $69 \mathrm{~g}$ of cotton cake and $97 \mathrm{~g}$ of fish meal and 4) $140 \mathrm{~g}$ of fish meal. Each diet supplied approximately $72 \mathrm{~g}$ protein per animal. Additionally all the animals received $200 \mathrm{~g}$ of alfalfa hay and had free access to water and barley straw treated with amonia. Daily weight gains were recorded, and all four diets produced similar ( $>00.05$ ) results: 1) 240, 2) 265,3 ) 276 and 4) 255 g/day. The results indicate, that under conditions of the present experiment, the addition of bypass protein to a diet including amonia treated straw fails to produce additional weight gain in sheep.

Key words: Amonia treatment, urea, bypass protein, fish meal, cotton cake, digestibility, sheep.
\end{abstract}

El presente estudio se llevó a cabo en el Centro Experimental IVITA-El Mantaro de la Facultad de Medicina Veterinaria de la UNMSM, con el objetivo de comparar en términos de ganancia de peso la inclusión de proteína sobrepasante (harina de pescado) en ovinos alimentados con residuo de cosecha tratada químicamente con urea (paja de cebada amonificada). Se usaron 56 ovinos hembra de la raza Junín en un diseño completamente al azar con cuatro tratamientos. Los tratamientos en estudio fueron: $230 \mathrm{~g}$ de pasta de algodón (Tratamiento 1); $161 \mathrm{~g}$ de pasta de algodón y $42 \mathrm{~g}$ de harina de pescado (Tratamiento 2); $69 \mathrm{~g}$ de pasta de algodón y $97 \mathrm{~g}$ de harina de pescado (Tratamiento 3); $140 \mathrm{~g}$ de harina de pescado (Tratamiento 4). Todos los animales recibieron aprox. $72 \mathrm{~g}$ de proteína. El porcentaje de sustitución fue sobre el nivel de proteína; así mismo, se les ofreció paja de cebada amonificada ad-libitum, $200 \mathrm{~g}$ de heno de alfalfa y agua a discreción. El estudio se realizó en los meses de junio-agosto (época seca) durante 21 días. Los promedios de ganancia de peso/día durante el período de estudio fueron similares ( $\mathrm{P}>0.05$ ), 240, 265, 276 y $255 \mathrm{~g}$ /día para los tratamientos 1, 2, 3 y 4, respectivamente. Bajo las condiciones del presente experimento se concluye que no hubo efecto positivo sobre la ganancia de peso en función a la inclusión de proteína sobrepasante en ovinos alimentados con paja amonificada.

Palabras clave: Amonificación, urea, proteína sobrepasante, harina de pescado, pasta de algodón, digestibilidad, ovinos.

\footnotetext{
'Práctica privada

${ }^{2}$ Laboratorio de Nutrición Animal - FMV-UNMSM
} 


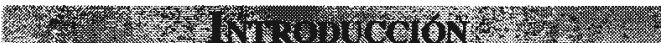

Los sistemas de producción animal en la sierra están basados principalmente en el uso de forrajes; sin embargo estos sistemas en ciertas épocas debido a la baja disponibilidad y bajo valor nutritivo de los forrajes presentan un desbalance entre los nutrientes ofertados y la demanda por los animales, limitando la productividad en estos sistemas.

Las condiciones climáticas de la sierra del Perú diferencia dos periodos bien definidos; un periodo corto de lluvias con abundante pasto de buena calidad y un periodo seco con escasez de forraje de bajo valor nutritivo. En este periodo seco los animales no logran cubrir sus requerimientos nutritivos jugando un papel importante en la alimentación del ganado los residuos de cosecha.

El uso de los residuos de cosecha por los rumiantes, principalmente de cereales, está ampliamente difundido. El valor nutritivo de estos insumos es bajo debido a la alta concentración de carbohidratos estructurales y bajo nivel proteico. La amonificación o tratamiento con urea de los residuos de cosecha es una alternativa para mejorar la calidad nutritiva a través de aumentos de la digestibilidad y del tenor proteico (Tovar et al; 1991).

Otra alternativa para elevar el rendimiento animal es el uso de proteína sobrepasante, que por sus características no es atacada por la población microbiana del rumenretículo de los rumiantes y llegando a nivel de abomaso e intestino delgado para su utilización directa por el animal. Uno de los insumos con alta proporción de proteína sobrepasante es la harina de pescado (Villanueva y San Martín, 1997).

Teniendo en cuenta los aspectos antes mencionados se planteó el presente trabajo de investigación con el objetivo de eva- luar la inclusión de proteína sobrepasante en las dietas de los ovinos alimentados con residuo de cosecha tratada químicamente (paja amonificada).

\section{MaTERIALs XMETodos}

El estudio se llevó a cabo en la Estación Experimental El Mantaro, del Instituto Veterinario de Investigaciones Tropicales y de Altura (IVITA) perteneciente a la Universidad Nacional Mayor de San Marcos, ubicado en el distrito del mismo nombre, provincia de Jauja, departamento de Junín. La estación se encuentra a una altitud de $3,320 \mathrm{~m}$, con una temperatura y precipitación promedio anual de $10.9^{\circ} \mathrm{C}$ y $750 \mathrm{~mm}$, respectivamente. Se utilizaron 56 ovinos hembras vacías, de la raza Junín, con edad y peso promedio de 4 años y $40 \mathrm{~kg}$, respectivamente; distribuidos al azar en cuatro tratamientos con 14 unidades experimentales cada uno. El experimento tuvo una duración de 21 días. Los animales estuvieron estabulados en corrales y fueron previamente dosificados contra nemátodos gastrointestinales y pulmonares.

A las 08:00 h., cada animal recibió paja de cebada amonificada (ad libitum) y a las 12:00 h., se les ofreció concentrado de acuerdo al tratamiento indicado. Los tratamientos en estudio fueron: $230 \mathrm{~g}$ de pasta de algodón (Tratamiento 1); $161 \mathrm{~g}$ de pasta de algodón y $42 \mathrm{~g}$ de harina de pescado (Tratamiento 2); $69 \mathrm{~g}$ de pasta de algodón y $97 \mathrm{~g}$ de harina de pescado (Tratamiento 3); $140 \mathrm{~g}$ de harina de pescado (Tratamiento 4). Todos los animales recibieron aprox. $72 \mathrm{~g}$ de proteína. El porcentaje de sustitución fue sobre el nivel de proteína; así mismo, se les ofreció paja de cebada amonificada ad libitum, $200 \mathrm{~g}$ de heno de alfalfa, y agua a discreción.

El tratamiento de la paja de cebada con urea al $5 \%$ consistió en disolver $5 \mathrm{~kg}$ de urea en 50 litros de agua. La solución se roció a 
$100 \mathrm{~kg}$ de paja. El total utilizado fue $100 \mathrm{~kg}$ de urea, 1000 litros de agua y $2000 \mathrm{~kg}$ de paja. El residuo tratado se cubrió con plástico por un periodo mínimo de 30 días antes de su consumo por los animales.

El control de peso de los animales se efectuó al inicio y cada 7 días del experimento. Para este efecto, los animales estuvieron en ayunas y el peso se registró a la misma hora $(07: 00 \mathrm{~h})$. El incremento de peso en los animales fue estimado por la regresión lineal donde el coeficiente de la regresión (b) es la ganancia diaria por animal.

Los insumos alimenticios del experimento además de la alfalfa patrón fueron sometidos al análisis químico nutricional (análisis proximal de Weende). La digestibilidad in vitro de la materia seca fue evaluada para hallar los parámetros digestivos de la paja sin tratar y tratada.

El diseño experimental empleado fue el de completamente al azar, con cuatro tratamientos y 14 unidades experimentales por tratamiento. Los parámetros medidos fueron sometidos al análisis de varianza (ANDEVA) En caso de encontrarse diferencias significativas en ANDEVA la diferencia entre tratamientos fue establecida por la prueba de rango múltiples (DMS) protegida. (Steel y Torrie, 1980; Wayne, 1996).

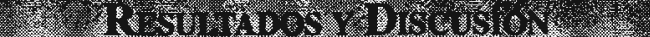

En el Cuadro 1, se presenta el resultado de los análisis. El proceso de amonificación elevó el contenido de proteína de la paja de cebada de 2.98 a $9.03 \%$ de materia seca.

El tratamiento químico con urea de la paja de cebada incrementó la digestibilidad en un $17.42 \%$ (de 54.41 a 63.89) y el contenido de proteína cruda en $203 \%$ (de 2.98 a 9.03). Así, en estudios previos Gutiérrez (1988) en un ensayo de digestión de la paja de cebada tratada con 3 y $5 \%$ de urea, en ovinos, determinó un incremento de digestibilidad de la materia seca de 20.9 y $38.5 \%$ y un incremento de la proteína cruda de 107 y $200 \%$ con respecto a la paja sin tratar, para ambos niveles de urea, respectivamente.

Al respecto, Tovar et al; (1991); menciona que la paja de cebada sometida al tratamiento químico presentó, en relación a la paja sin tratar, incrementos en el contenido de proteína cruda en un $50 \%$ (de 3.06 a 4.59) $y$ digestibilidad en un $12 \%$ (de 53 a 59).

El aumento de la digestibilidad de la paja tratada tiene la ventaja de favorecer un mayor consumo de material fibroso de baja calidad disponiéndose de esta manera mas energía (Tripathi et al., 1987), para una mejor conversión alimenticia en ovinos y vacunos. Los cambios descritos tanto en la

Cuadro 1. Análisis químico proximal y digestibilidad in vitro de los insumos (\%)

\begin{tabular}{lcccccc}
\hline Insumos & $\begin{array}{c}\text { Proteína } \\
\text { cruda }\end{array}$ & $\begin{array}{c}\text { Extracto } \\
\text { etéreo }\end{array}$ & $\begin{array}{c}\text { Fibra } \\
\text { cruda }\end{array}$ & Cenizas & $\begin{array}{c}\text { Extracto no } \\
\text { nitrogenado }\end{array}$ & $\begin{array}{c}\text { Digestibilidad } \\
\text { in vitro }\end{array}$ \\
\hline Paja sin tratar & 2.98 & 1.33 & 37.9 & 4.53 & 53.26 & 54.41 \\
Paja amonificada & 9.03 & 1.02 & 34.95 & 5.13 & 49.87 & 63.89 \\
Heno de alfalfa & 8.44 & 1.54 & 36.61 & 5.97 & 47.44 & 61.53 \\
Pasta de algodón & 41.63 & 0.46 & 13.95 & 2.83 & 41.13 & 71.14 \\
Harina de pescado & 66.33 & 4.94 & -- & 18.55 & 10.18 & 85.16 \\
Alfalfa patrón & 19.31 & 1.90 & 28.77 & 8.92 & 41.10 & 69.16 \\
\hline
\end{tabular}


digestibilidad como en la proteína permitirían mejorar el aprovechamiento de la paja tratada con urea por las bacterias ruminales para su digestión; así mismo, mejorarían el equilibrio del nitrógeno de los animales, lo cual es corroborado por varios autores (Brown et al., 1987; Saha y Gupta, 1989; Trung et al., 1989; Kumar et al., 1991; Tuen et al., 1991; Ramana et al., 1990).

Al evaluar la ganancia de peso (Figura 1), se observó que los animales que recibieron proteína sobrepasante (T2, T3, y T4) tuvieron, en promedio, similares ganancias de peso con respecto a los animales que no recibieron dicha proteína (T1). Los promedios de ganancia de peso/día durante el período de estudio fueron similares $(\mathrm{P}>0.05)$, 241 (T1), 265 (T2), 276(T3) y 255 (T4).

Carrión (1982), observó en ovinos de engorde que la inclusión de harina de pescado a una dieta basal fibrosa, incrementó la ganancia de peso de -28 a 108 g/día. El efec- to de la harina de pescado fue atribuido a su baja solubilidad (30\% en dicho experimento), que habría permitido una mayor disponibilidad de aminoácidos a nivel intestinal, los cuales, según Nolan et al., (1986), son metabólicamente "flexibles", ya que no sólo corrigen deficiencias de aminoácidos esenciales, sino que pueden generar glucosa a través del proceso de gluconeogénesis.

Se sabe que las harinas de origen animal (pescado) son las fuentes más ricas en proteína sobrepasante. Los residuos de la extracción de aceites vegetales son intermedios y los forrajes los más pobres en contenido de proteína sobrepasante (NRC, 1985).

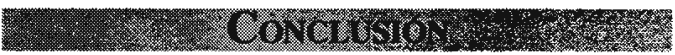

Bajo las condiciones del presente experimento se concluye que no hubo efecto positivo sobre la ganancia de peso en función a la inclusión de proteína sobrepasante en ovinos alimentados con paja amonificada.

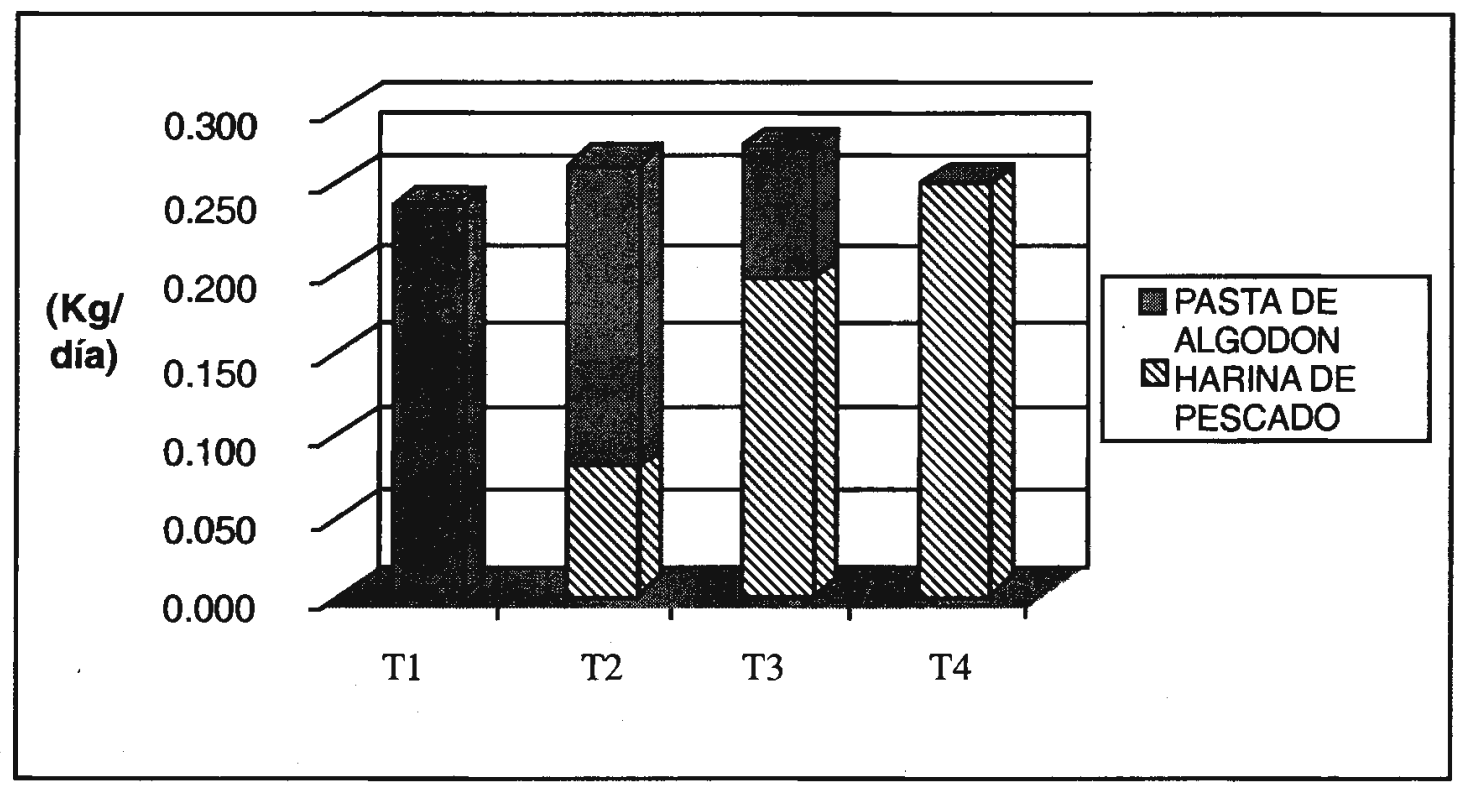




\section{Minantura Criabs}

1. Brown, W. F.; J. D. Philips y D. B. Jones. 1987. Amoniation of cane molasses suplementation of low quality forages. J. Animal Sci. 64:1205-1214.

2. Carrión, G. 1982. Optimización del uso de subproductos agroindustriales en dietas de ovinos en crecimiento mediante la suplementación de NNP, proteína y energía sobrepasante. Tesis. Ing. Zootecnista UNALM, Lima. p. 126.

3. Gutierrez, L. 1998. Caracterización de la digestión de la paja de cebada tratada con urea evaluada en ovinos. Tesis Ing. Zootecnista. UNALM, Lima. Perú, p. 143.

4. Kumar, R. D.; K. N. Naidu y N. Krishna. 1991. Effect of feeding urea treated paddy straw on the performance and nutrient digestibility in crossbred cow. J. Dairy Sci., Indian, 44:196-199.

5. N.R.C. 1985. Ruminant nitrogen usage. National Academy press. Washington, D.C.

6. Nolan, J. V.; G. J.Lee; D. W. Hennessy $y$ R. A. Leng. 1986. "Metabolic responses to supplementation in growing ruminants consuming low digestibility, fibrous diets. Preprint of the International Symp. on the use of nuclear tech". In studies of Anim. Prod. and Health in different environments. Viena.

7. Ramana, J. V.; N. Krishna; M. Parthasarathy y J. R. Prasad. 1990. Effect of urea treatment on the protein degradability of pearl millet straw. J. Anim. Sci.., Indian, 60:1022-1023.

8. Saha, R. C. y B. N. Gupta. 1989. Effect of feeding different levels of urea as protein replacer on growth and nutrient utilization in crossbred calves. J. Dairy Sci., Indian, 42:413-418.
9. Steel, R.D.G. y J.H. Torrie. 1980. Principles and procedures of statistics. A Biometrical Approach. 2da. ed. Mc. Graw-Hill Book Company. New York, USA, p. 616.

10. Tovar, A.; C. Bojórquez y F. San Martín. 1991. Consumo voluntario de paja de cebada entera, picada y tratada con urea en llamas, alpacas y ovinos. Rev. Investigaciones sobre pastos y forrajes de Texas Tech University en el Perú, 6:55-56.

11. Tripathi, A. K.; R. Manget ; A. K. Mehta y J. L. Kukreja. 1987. Effect of various methods of treatment on in vitro dry matter digestibility and crude protein conteins of rice straw using urea or ammonia as chemical. J. Dairy Sci., Indian, 40:174-178.

12. Trung, L. T.; N. B. Rajwar; N. B. Velazco; P. Q. Vinh y L. P. Palo. 1989. Urea treated vs. Urea-molasses-sprayed rice straw with two concentrate feeding frecuencies for yearling Brahman grades. J. Vet. and Anim. Sci., Philippine, 15:9-21.

13. Tuen, A.; M. Dahan; B. A. Young y $P$. Vijchulata. 1991. Intake and digestion of urea treated, urea supplemented and untreated rice straw by goats. Anim. Feed Sci. and Technology. 32:333-340.

14. Villanueva, J. y F. San Martín. 1997. Alimentación de vaquillas en crecimiento a base de residuos de cosecha tratada con urea y suplementadas con proteína sobrepasante. Rev. Inv. Pec. IVITA (Perú) 8 (1): 39-48.

15. Wayne, D. 1996. Bioestadística. Base para el análisis de las ciencias de la salud. 5ta. ed., p. 203. Editorial Limusa S.A. D.C.V. Grupo Noriega editores. Balderas-México D.F. 